\title{
ANALISIS KINERJA PEGAWAI PADA KANTOR KEMENTERIAN AGAMA KABUPATEN LABUHANBATU UTARA
}

\author{
Hayanuddin Safri dan Raja Saul Marto Hendry \\ Dosen Fakultas Ekonomi dan Bisnis Universitas Labuhanbatu \\ Email: Ehayanuddinhrp@gmail.com
}

\begin{abstract}
Abstrak
Secara Parsial Disiplin Kerja Berpengaruh Positif dan Signifikan Terhadap Kinerja Kerja Pada Kementerian Agama Kabupaten Labuhanbatu Utara dengan nilai $\left.t_{\text {hitung }}(3,964)>t_{\text {tabel }} 1,710\right)$ dan taraf signifikasi $0,001<0,05$. Secara Parsial Disiplin Kerja Berpengaruh Positif dan Signifikan Terhadap Kinerja Kerja Pada Kementerian Agama Kabupaten Labuhanbatu Utara dengan nilai thitung yaitu $(3,339)>t_{\text {tabel }}(1,710)$ dan taraf signifikansi 0,003<0,05. Secara Parsial Etika Kerja Berpengaruh Positif Dan Signifikan Terhadap Kinerja Kerja Pada Kementerian Agama Kabupaten Labuhanbatu Utara dengan nilai $t_{\text {hitung }}$ yaitu $(5,107)>t_{\text {tabel }}$ $(1,710)$ dan taraf signifikansi $0,000<0,05$. Secara Parsial Lingkungan Kerja Berpengaruh Positif Dan Signifikan Terhadap Kinerja Kerja Pada Kementerian Agama Kabupaten Labuhanbatu Utara dengan nilai $t_{\text {hitung }}$ yaitu $(3,907)>t_{\text {tabel }}$ $(1,710)$ dan taraf signifikansi 0,001<0,05.Secara simultan Motivasi Kerja, Disiplin Kerja, Etika Kerja dan Lingkungan Kerja berpengaruh positif dan signifikan terhadap Kinerja Kerja Pada Kementerian Agama Kabupaten Labuhanbatu Utara dengan hasil penelitian menunjukkan bahwa nilai $F_{\text {hitung }}$ yaitu $(11,330)>F_{\text {tabel }}$ $(2,76)$ dan taraf signifikasi $0,00<0,05$.
\end{abstract}

Kata kunci; Motivasi kerja, Disiplin kerja, Etika kerja, Lingkungan kerja, Kinerja Pegawai

\section{PENDAHULUAN}

Kinerja merupakan bagian dari bentuk perilaku seorang karyawan dalam bekerja yang ditunjukan dalam wujud prestasi kerja yang sesuai dengan perannya di dalam suatu perusahaan yang memiliki jangka waktu tertentu. Hal ini disebabkan karena kinerja kerja yang menentukan keberhasilan suatu perusahaan serta untuk kelangsungan hidup perusahaan itu sendiri. Dalam setiap organisasi, manusia merupakan salah satu komponen yang sangat penting dalam menghidupkan organisasi tersebut. Hal ini harus didukung dengan kinerja yang baik pula karena tanpa kinerja yang baik, organisasi tidak akan mencapai tujuannya.

Faktor yang dapat mempengaruhi kinerja kerja seseorang adalah motivasi kerja, suatu organisasi memerlukan pegawai yang memiliki kemauan tinggi serta semangat dalam bekerja untuk mencapai hasil yang optimal, untuk mendapatkan suatu hasil yang optimal diperlukan sebuah motivasi dalam bekerja agar tercapainya suatu tujuan yang diinginkan. 
Kedisplinan pegawai merupakan salah satu faktor yang juga mempengaruhin tingkat kinerja pegawai, karena disiplin kerja merupakan hal yang diperlukan dalam setiap kegiatan kerja agar sesuai dengan peraturan dan tata tertib. Permasalahan yang terjadi pada kantor Kementerian Agama Kabupaten Labuhanbatu Utara masih kurangnya pemberian motivasi dari atasan ke bawahan sehingga para pegawai kurang bersemangat dalam bekerja, hal ini terlihat dari pegawai yang masih ada bermalas-malasan dalam bekerja, pemberian insentif yang diberikan oleh Kementerian Agama Kabupaten Labuhanbatu Utara belum cukup untuk memotivasi pegawai untuk meningkatkan kinerjanya.

Penurunan kinerja juga dapat dilihat dari disiplin kerja pada kantor Kementerian Agama Kabupaten Labuhanbatu Utara seperti dari jam masuk kerja para pegawai, serta pada saat waktu jam kerja masih ada para pegawai tidak berada pada tempatnya masing-masing. Kondisi lingkungan kerja yang nyaman juga dapat menjadikan pegawai tidak bersemangat dalam menjalankan kegiatan pekerjaanya, datang tidak tepat waktu, tapi sebaliknya apabila lingkungan kerja memberikan rasa nyaman, maka pegawai akan bersemangat dalam menjalankan aktivitas pekerjaan yang akan mempengaruhi kinerja agar lebih optimal dalam menjalankan tugas dan kewajibannya.

Etika kerja merupakan faktor yang juga dapat mempengaruhi kinerja kerja, etika sangat penting dunia kerja karena etika menjadi kunci atau panduan dalam profesionalisme kerja. Etika kerja dibuat untuk para pekerja agar lebih disiplin dengan menaatin etika yang berlaku ditempat kerja sehingga dapat memperlancar kinerja kerja sehari-harinya.

\section{KAJIAN TEORI}

\subsection{Motivasi Kerja}

Robbins dan Judge (2011) mendefeniskan motivasi sebagai suatu proses yang menjelaskan intensitas, arah dan ketekunan individu agar dapat mencapai tujuannya. Motivasi menjadi sebagai suatu kecenderungan untuk beraktivitas, mulai dari dorongan dalam diri dan kebutuhan yang distimulasi yang berorientasi kepada tujuan individu.

\section{a. Faktor-Faktor Motivasi Kerja}

Faktor-faktor motivasi yang diuraikan dalam hal ini dikutip dari teori dua faktor Herzberg. Faktor-faktor motivasi tersebut adalah sebagai berikut:

1. Gaji (Salary)

2. Supervisi

3. Kebijakan dan Administrasi

4. Hubungan Kerja

5. Kondisi Kerja

6. Pekerjaan itu sendiri

7. Peluang untuk maju (advance)

8. Keberhasilan (achievement)

9. Tanggung Jawab 


\subsection{Disiplin Kerja}

Dessler (2012) mengemukakan disiplin adalah suatu prosedur untuk mengoreksi atau menghukum seorang pegawai sesuai dengan peraturan yang ditetapkan kepada yang bersangkutan karena melanggar peraturan yang diberikan kepadanya. Kaitannya terhadap pekerjaan, faktor disiplin dipandang sebagai suatu tindakan untuk mengoreksi perilaku dan sikap yang salah pada pegawai.

\section{b. Bentuk-Bentuk Disiplin}

Menurut Handoko (2010) bentuk- bentuk disiplin dibedakan atas 3 (tiga) kategori yaitu:

1. Disiplin Preventif (Preventive discipline).

2. Disiplin Korektif (Corrective discipline).

3. Disiplin Progresif (Progresive dicipline)

\subsection{Etika Kerja}

Menurut Ali \& Al-Owaihan (2012) etika kerja islam merupakan orientasi untuk membentuk serta mempengaruhi keterlibatan dan partisipasi pengikutnya di lingkungan tempat ia bekerja. Etika kerja islam yang melihat kerja merupakan sebagai sarana dalam meningkatkan kepentingan seseorang individu dalam bentuk ekonomi, psikologis maupun sosial, demi mempertahakan prestise sosial, dalam mensejahterakan masyarakat serta meningkatkan kembali iman.

Terdapat sepuluh nilai yang diidentifikasikan dan dijelaskan oleh Josephson dalam Teaching ethical Decision Making and Principle Rasioning. Kesepuluh nilai tersebut adalah:

1) Kejujuran (honesty)

2) Integritas (integrity)

3) Memegang janji (promise keeping)

4) Kesetiaan (fidelity)

5) Keadilan (fairness)

6) Kepedulian terhadap sesamanya (carring for others)

7) Penghargaan terhadap orang lain (respect forother)

8) Kewarganegaraan yang bertanggung jawab (responsible citizenship)

9) Pencapaian kesempurnaan (pursuit of excellence)

10) Akuntabilitas (accountability).

\subsection{Lingkungan Kerja}

Nitisemito (2012) mendefinisikan lingkungan kerja sebagai: "Segala sesuatu yang ada di sekitar para pekerja yang dapat mempengaruhi dirinya dalam menjalankan tugas-tugas yang diembankan".

\section{a. Jenis Lingkungan Kerja}

Menurut Sedarmayanti (2011), secara garis besar jenis lingkungan kerja terbagi menjadi dua, yaitu:

a. Lingkungan kerja fisik

b. Lingkungan kerja non fisik 


\section{Kerangka Konseptual}

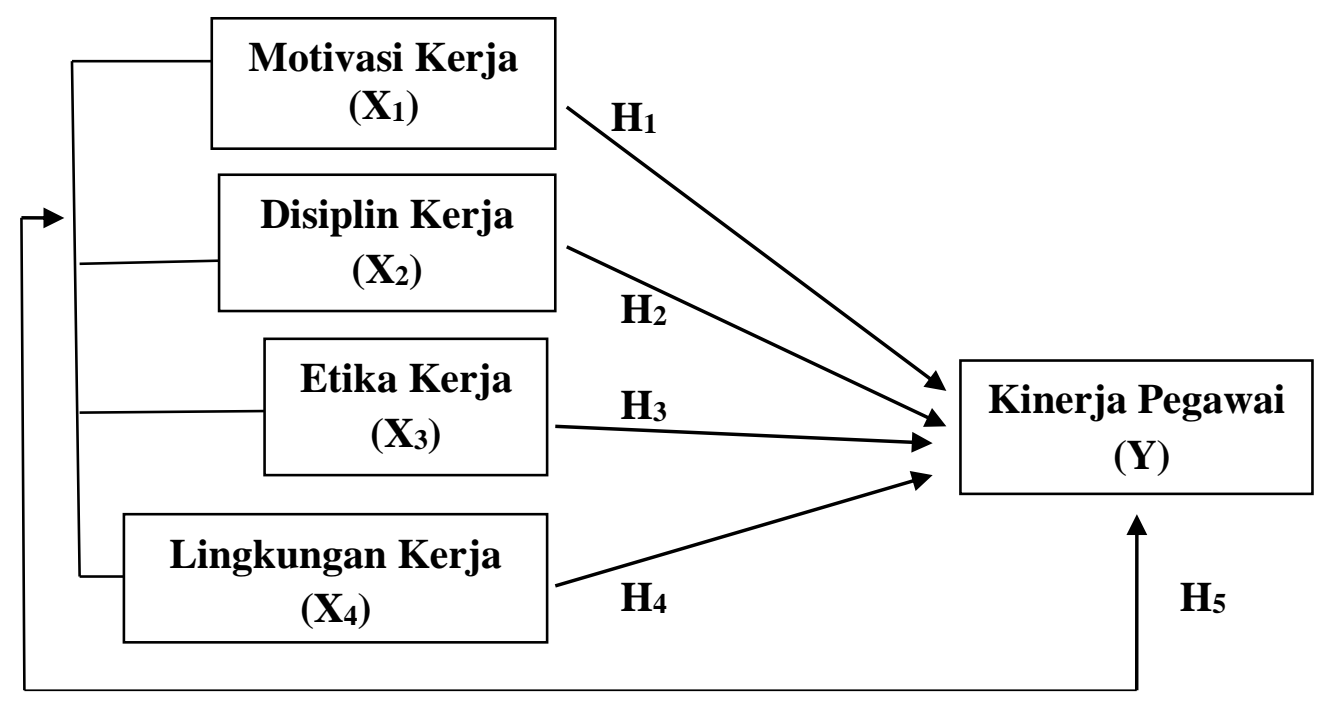

\section{III.Teknik Pengumpulan Data}

Teknik pengumpulan data dalam penelitian ini adalah kuesioner dan wawancara. Menurut Sugiyono (2010), teknik pengumpulan data meliputi:

a. Wawancara (Interview)

Wawancara digunakan sebagai teknik pengumpulan data apabila peneliti ingin melakukan studi pendahuluan untuk menemukan permasalah yang harus diteliti, dan juga apabila peneliti ingin mengetahui hal-hal dari responden yang lebih 83eliabl dan jumlah respondennya sedikit atau kecil. Teknik pengumpulan data ini mendasarkan diri pada laporan tentang diri sendiri atau self report, atau setidak-tidaknya pada pengetahuan atau keyakinan pribadi.

b. Kuesioner

Kuesioner merupakan teknik pengumpulan data yang dilakukan dengan cara memberi seperangkat pertanyaan atau pernyataan tertulis kepada responden untuk dijawabnya. Kuesioner merupakan teknik pengumpulan data yang efisien bila peneliti tahu dengan pasti variable yang akan diukur dan tahu apa yang bisa diharapkan dari responden. Selain itu kuesioner juga cocok digunakan bila jumlah responden cukup besar dan tersebar di wilayah yang luas. Kuesioner dapat berupa pertanyaan/pernyataan tertutup atau terbuka, dapat diberikan kepada responden secara langsung atau dikirim melalui pos atau internet.

IV. Metode Analisis Data

1. Metode Analisis Statistik

a. Analisis Regresi Linier Berganda 
Bentuk dari persamaan regresi linear berganda yang digunakan dalam penelitian ini dapat dirumuskan:

$$
\mathbf{Y}=\mathbf{a}+\mathbf{b}_{1} \mathbf{X}_{1}+\mathbf{b}_{2} \mathbf{X}_{2}+\mathbf{b}_{3} \mathbf{X}_{3}+\mathbf{b}_{4} \mathbf{X}_{4}+\mathbf{e}
$$

Keterangan:

$\begin{array}{ll}\mathrm{Y} & =\text { Kinerja } \\ \mathrm{a} & =\text { Konstanta } \\ \mathrm{b}_{1}-\mathrm{b}_{2}-\mathrm{b}_{3}-\mathrm{b}_{4} & =\text { Koefisien Regresi } \\ \mathrm{X}_{1} & =\text { Motivasi Kerja } \\ \mathrm{X}_{2} & =\text { Disiplin Kerja } \\ \mathrm{X}_{3} & =\text { Etika Kerja } \\ \mathrm{X}_{4} & =\text { Lingkungan Kerja } \\ \mathrm{e} & =\text { Standard Error }\end{array}$

V. PEMBAHASAN

Tabel1. Hasil Analisis Regresi Linear Berganda

\begin{tabular}{|c|c|c|c|c|c|c|}
\hline \multicolumn{7}{|c|}{ Coefficients $^{a}$} \\
\hline \multirow{2}{*}{\multicolumn{2}{|c|}{ Model }} & \multicolumn{2}{|c|}{ Unstandardized Coefficients } & \multirow{2}{*}{$\begin{array}{l}\text { Standardized } \\
\text { Coefficients } \\
\text { Beta }\end{array}$} & \multirow[t]{2}{*}{$\mathrm{t}$} & \multirow[t]{2}{*}{ Sig. } \\
\hline & & B & Std. Error & & & \\
\hline \multirow{5}{*}{1} & (Constant) & 7.112 & 3.040 & & 2.340 & .028 \\
\hline & Motivasi Kerja & .855 & .216 & .788 & 3.964 & .001 \\
\hline & Disiplin Kerja & .442 & .132 & .404 & 3.339 & .003 \\
\hline & Etika Kerja & .554 & .108 & .667 & 5.107 & .000 \\
\hline & Lingkungan Kerja & .670 & .171 & .731 & 3.907 & .001 \\
\hline
\end{tabular}

a. Dependent Variable: Kinerja

Sumber: Hasil Penelitian (Data diolah SPSS), 2020 berikut:

Dari nilai tersebut dapat dibentuk suatu model persamaan regresi sebagai

$$
Y=7,112+0,855 X_{1}+0,442 X_{2}+0,554 X_{3}+0,670 X_{4}+e
$$

Hasil Uji Hipotesis

a. Uji Signifikansi Parsial (Uji t)

Tabel 5.1

\begin{tabular}{|c|c|c|c|c|c|}
\hline \multicolumn{6}{|c|}{ Coefficients $^{a}$} \\
\hline \multirow[t]{2}{*}{ Model } & \multicolumn{2}{|c|}{ Unstandardized Coefficients } & Standardized & \multirow[t]{2}{*}{$\mathrm{t}$} & \multirow[t]{2}{*}{ Sig. } \\
\hline & B & Std. Error & Beta & & \\
\hline $1 \quad$ (Constant) & 7.112 & & & 2.340 & .028 \\
\hline
\end{tabular}

Hasil Uji Parsial (Uji t) 


\begin{tabular}{|l|r|r|r|r|r|}
\hline Motivasi Kerja & .855 & .216 & .788 & 3.964 & .001 \\
Disiplin Kerja & .442 & .132 & .404 & 3.339 & .003 \\
Etika Kerja & .554 & .108 & .667 & 5.107 & .000 \\
Lingkungan Kerja & .670 & .171 & .731 & 3.907 & .001 \\
\hline
\end{tabular}

a. Dependent Variable: Kinerja

Sumber: Hasil Penelitian (Data diolah SPSS), 2020

\section{b. Uji Signifikansi Simultan (Uji F)}

Tabel 5.2

Hasil Uji Simultan (Uji F)

\begin{tabular}{|c|c|c|c|c|c|c|}
\hline \multicolumn{2}{|c|}{ Model } & Sum of Squares & $\mathrm{Df}$ & Mean Square & $\mathrm{F}$ & Sig. \\
\hline \multirow{3}{*}{1} & Regression & 67.907 & 4 & \multirow{3}{*}{$\begin{array}{r}16.977 \\
1.498\end{array}$} & \multirow[t]{3}{*}{11.330} & \multirow[t]{3}{*}{$.000^{\mathrm{b}}$} \\
\hline & Residual & 37.460 & 25 & & & \\
\hline & Total & 105.367 & 29 & & & \\
\hline
\end{tabular}

a. Dependent Variable: Kinerja

b. Predictors: (Constant), Lingkungan Kerja, Disiplin Kerja, Etika Kerja, Motivasi Kerja

\section{c. Koefisien Determinasi}

Tabel 5.3

Koefisien Determinasi

\begin{tabular}{|l|r|r|r|r|}
\hline \multicolumn{2}{|c|}{ Model Summary $^{\mathrm{b}}$} \\
& $\mathrm{R}$ & R Square & Adjusted R Square & $\begin{array}{c}\text { Std. Error of the } \\
\text { Estimate }\end{array}$ \\
\hline 1 & $.803^{\mathrm{a}}$ & .644 & .588 & 1.224 \\
\hline
\end{tabular}

a. Predictors: (Constant), Lingkungan Kerja, Disiplin Kerja, Etika Kerja, Motivasi Kerja b. Dependent Variable: Kinerja

\section{Kesimpulan}

Kesimpulan yang dirumuskan penulis berdasarkan perumusan masalah dalam penelitian ini adalah:

1. Secara Parsial Disiplin Kerja Berpengaruh Positif dan Signifikan Terhadap Kinerja Kerja Pada Kementerian Agama Kabupaten Labuhanbatu Utara dengan nilai $\left.t_{\text {hitung }}(3,964)>t_{\text {tabel }} 1,710\right)$ dan taraf signifikasi $0,001<0,05$.

2. Secara Parsial Disiplin Kerja Berpengaruh Positif dan Signifikan Terhadap Kinerja Kerja Pada Kementerian Agama Kabupaten Labuhanbatu Utara dengan nilai $t_{\text {hitung }}$ yaitu $(3,339)>\mathrm{t}_{\text {tabel }}(1,710)$ dan taraf signifikansi $0,003<$ 0,05 .

3. Secara Parsial Etika Kerja Berpengaruh Positif Dan Signifikan Terhadap Kinerja Kerja Pada Kementerian Agama Kabupaten Labuhanbatu Utara 
dengan nilai $t_{\text {hitung yaitu }(5,107)>t_{\text {tabel }}(1,710) \text { dan taraf signifikansi } 0,000<}$ 0,05 .

4. Secara Parsial Lingkungan Kerja Berpengaruh Positif Dan Signifikan Terhadap Kinerja Kerja Pada Kementerian Agama Kabupaten Labuhanbatu Utara dengan nilai thitung yaitu $(3,907)>t_{\text {tabel }}(1,710)$ dan taraf signifikansi $0,001<0,05$.

5. Secara simultan Motivasi Kerja, Disiplin Kerja, Etika Kerja dan Lingkungan Kerja berpengaruh positif dan signifikan terhadap Kinerja Kerja Pada Kementerian Agama Kabupaten Labuhanbatu Utara dengan hasil penelitian

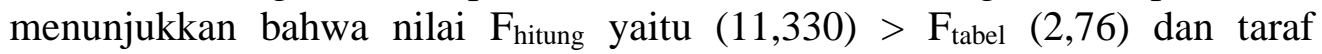
signifikasi $0,00<0,05$.

\section{Saran}

Dalam penelitian ini, penulis memberikan saran kepada pihak-pihak yang berkepentingan pada penelitian ini, antara lain:

1. Kementerian Agama Kabupaten Labuhanbatu Utara dalam memperhatikan etika kerja para pegawai nya sehingga para pegawai merasa nyaman secara emosional dalam bekerja yang dapat meningkatkan kinerjanya dalam bekerja.

2. Kementerian Agama Kabupaten Labuhanbatu Utara diharapkan untuk lebih memperhatikan lingkungan kerja dan disiplin kerja para pegawainya agar para pegawai bekerja secara maksimal.

3. Kementerian Agama Kabupaten Labuhanbatu Utara diharapkan agar dapat memotivasi para pegawai nya agar dapat bekerja secara optimal dan mencapai tujuan dari organisasi.

4. Bagi peneliti-peneliti selanjutnya diharapkan dapat melakukan penelitian dengan menggunakan variabel yang berbeda dengan variabel yang diteliti dalam penelitian ini sehingga dapat memperoleh hasil yang lebih bervariatif yang dapat berpengaruh terhadap Kinerja Kerja.

\section{DAFTAR PUSTAKA}

Alex. S. Nitisemito, 2012, Manajemen Personalia. Edisi Revisi, Penerbit Ghalia Indonesia

Ahmad, Amins. 2012. Manajemen Kinerja Pemerintah Daerah. Yogyakarta: LaksBang PRESSindo.

Bedjo Siswanto. Sastrohadiwiryo. 2012. "Manajemen Tenaga Kerja Indonesia". Jakarta: PT. Bumi Aksara.

Davis, Keith and John. W. Newstrom. 2010. Perilaku Dalam Organisasi Jilid 1 dan 2. Jakarta, Erlangga

Dessler, Gary, 2012. Manajemen Sumber Daya Manusia. Indeks. Jakarta

Edison Emron, Yohny Anwar dan Imas Komariah., 2015. Manajemen Sumber Daya Manusia, Alfabeta, Bandung

Fathoni, Abdurrahman, 2012. Manajemen Sumber Daya Manusia, PT Rineka Cipta, Jakarta. 
Handoko, T. Hani. 2013. Manajemen Personalia dan Sumber Daya Manusia.Yogyakarta:BPFE.

Handoko, T Hani. 2010. Manajemen. Edisi 2. Yogyakarta : BPFE.

Hasibuan, Malayu S.P. 2012. Manajemen Sumber Daya Manusia, Edisi Revisi, Jakarta: Bumi Aksara.

Aksan, Hermawan. 2014. Pendidikan Budaya dan Karakter Bangsa. Bandung: Nuansa Cendekia

Henry Simamora, 2012. Manajemen Sumber Daya Manusia. Edisi 1. Yogyakarta: STIE YKPN Yogyakarta.

Kusuma, 2013. Pengaruh Motivasi dan Lingkungan Kerja terhadap Kinerja Karyawan Hotel Muria Semarang.

Mangkunegara, AA. 2012. Evaluasi Kinerja SDM. Refika Aditema. Bandung.

Mathis Robert L dan Jackson John H. 2011. Human Resource Management, Edisi 10, Jakarta: Salemba Empat

Notoatmodjo,s. 2010. Metodologi Penelitian Kesehatan. Jakarta : Rineka Cipta

Rivai, Vethzal \& Basri 2011. Performance Appraisal: Sistem Yang Tepat Untuk Menilai Kinerja Karyawan dan Meningkatkan Daya saing Perusahaan. Jakarta: PT. Raja Grafindo Persada.

Riska Hernayanti Pajar, Mahendra Fakhri, 2018. Pengaruh Etika Kerja

Terhadap Kinerja Karyawan Rumah Makan Ponyo Cinunuk Bandung

Sidanti, 2015. Pengaruh Lingkungan Kerja, Disiplin Kerja dan Motivasi Kerja Terhadap Kinerja Pegawai Negeri Sipil di Sekretariat DPRD Kabupaten Madiun

Sofyandi. 2011. Manajemen Sumber Daya Manusia. Bandung : Ghalia.

Sedarmiyati. 2011. Manajemen Sumber Daya Manusia Reformasi Birokrasi. Jakarta : Gremia Pustaka.

Siagian, Sondang P. 2012, Manajemen Sumber Daya Manusia, Cetakan Kelimabelas, Bumi Aksara, Jakarta.

Siswanto, HB, 2012 Pengantar Manajemen, Cetakan Kelima, Penerbit Bumi Aksara, Jakarta.

Sugiyono, 2010. Metode Penelitian Kuantitatif kualitatif dan R\&D, Alfabeta, Bandung.

Sutrisno, Edy, 2010. Manajemen Sumber Daya Manusia. Jakarta : Kencana.

Sumarsono. 2010. Sosiolinguistik. Yogyakarta: Pustaka Pelajar.

Situmorang dan Lufti, 2014. Analisis Data untuk Riset Manajemen dan Bisnis, USU Press, Medan.

Thoha. Miftah. 2010. Manajemen Sumber Daya Manusia. Jakarta : Rineka Cipta.

Wirawan. 2012. Evaluasi Kinerja Sumber Daya Manusia: Teori Aplikasi dan Penelitian. Jakarta: Salemba Empat. 